www.jmscr.igmpublication.org

Index Copernicus Value: 79.54

ISSN (e)-2347-176x ISSN (p) 2455-0450

crossref DOI: https://dx.doi.org/10.18535/jmscr/v7i4.85

\title{
A Case Report on Neuroleptic Malignant Syndrome Induced by Antipsychotic drugs and Lithium
}

Authors

\section{P.Bhavana $^{1}$, A.Yuva Sri Sai ${ }^{2}$, G. Sravanajyothi ${ }^{1}$, K.S.S. Tanuja ${ }^{1}$, Dr T.Srinivasa Rao \\ ${ }^{1}$ Pharm.D Intern, Nirmala College of Pharmacy, Atmakuru, Mangalagiri, Guntur Dt, Andhra Pradesh. \\ ${ }^{2}$ Associate Professor, Department of Pharmacy Practice. Nirmala College of Pharmacy, Atmakuru, \\ Mangalagiri, Guntur Dt, Andhra Pradesh.}

${ }^{3}$ Chief Intensivist, Manipal Hospital, Vijayawada, Krishna Dt, Andhra Pradesh.

*Corresponding Author

P.Bhavana

Pharm.D, Nirmala College of Pharmacy, Mangalagiri, Guntur -522503

Mobile: 9573318501, Email: bhvanap.1995@gmil.com

\begin{abstract}
Over the years, there is an increase in the prescribing of antipsychotics among elderly patients, and these are used for various clinical indications such as psychotic disorders, affective disorders, behavioural and psychological symptoms of dementia and delirium. Suspicion of neuroleptic malignant syndrome (NMS) is a frequent cause of emergent psychiatric consultation. We are reporting a case involving a 48yrs female patient had bipolar disorder and hypertension; she treated with neuroleptic drugs and lithium since 20years. Now she again came with the complaints of altered sensorium, generalized weakness, muscle rigidity, forgetfulness and cough. Finally diagnosed as Neuroleptic malignant syndrome (NMS). NMS is characterized by altered sensorium, generalized weakness, muscle rigidity, and an elevated creatine kinase level. This condition develops after a sudden increase in the dosage of the Neuroleptic medications and Lithium Toxicity. Treatment is mainly withdrawing of neuroleptic medications and supportive measures and possibly administration of bromocriptine, Amantadine, Antibiotics, corticosteroids, vasopressors and vitamin supplements. Complications of NMS include acute kidney failure and acute respiratory failure. Given the widespread prescription by physicians in a variety of fields. All physicians need to be able to recognize and appropriate management for NMS.
\end{abstract}

Keywords: Neuroleptic Malignant Syndrome, Antipsychotic drugs, Lithium, Neuroleptic drugs, Antidepressants, Hyperthermia, Autonomic dysfunction.

\section{Introduction}

Neuroleptic malignant syndrome (NMS) is a rare but life-threatening complication of antipsychotic therapy. The main clinical symptoms are fever, altered mental status, muscle rigidity, delirium, hyperthermia and autonomic dysfunction. NMS has been associated with virtually all neuroleptic drugs, mainly involved in newer atypical antipsychotics. It has also been reported with lithium and antidepressants, especially when combined with antipsychotics, as well as a variety of other medications that affects the central 
dopaminergic neurotransmission. ${ }^{1,2}$ Nonspecific laboratory findings are elevated CPK values, hyperkalaemia and hypernatremia. Death may occur due to cardiovascular collapse, renal or respiratory insufficiency and dysarythymia. ${ }^{3}$ Early diagnosis and proper therapeutic approach are necessary to avoid serious medical complications, expenses, and certain invasive medical procedures (i.e., brain computerized scan, lumbar puncture, unnecessary antibiotics, etc.). ${ }^{4}$ Treatment includes immediately stopping the offending agent and implementing supportive measures, as well as pharmacological interventions in more severe cases.1Maintaining vigilant awareness of the clinical features of NMS to diagnose and treat the disorder early, however, remains the most important strategy by which physicians can keep mortality rates low and improve patient outcomes.

\section{Discussion}

A 48 years female patient presented to the causality on 23/9/2018 in unconscious state with 15 days history of altered sensorium, generalized weakness, muscle rigidity, forgetfulness and cough. She had 20 years history of bipolar disorder and hypertension. ${ }^{5}$ The patient was taking treatment in local psychiatric hospital from past 20 years and she was taking Risperidone $4 \mathrm{mg}$, Lithium 450mg, Trihexyphenidyl 2mg, Olmesartan 20mg, Rosuvastatin + Fenofibrate $5 \mathrm{mg}$. From the last six months, she did not went to monitor lithium levels in plasma, but continuously she taken lithium tablet daily. Recently she visited psychiatric hospital with the complaints of forgetfulness \& aggressiveness, then physician given Inj. Phenergan, after Inj.Phenergan was taken; she went to unconscious state, and immediately shifted to apple hospital for further management. In that hospital physical examinations showed - Patient is in stupor, Unconscious, Febrile, Neck rigidity and Kernig's sign is present. Her Blood pressure is $160 / 80$ $\mathrm{mmHg}$, Pulse rate is $80 \mathrm{~b} / \mathrm{min}$, Respiratory rate is 28breaths/min and $\mathrm{SpO} 2$ is $100 \%$ @ 4 lit O2, Temp- 100F, GCS is E1V1M1. In apple hospital they treated with Inj. Monocef $2 \mathrm{gm}$, Inj. Decadran 2mg, Inj. Pantoprazole 40mg, Tab. Lithium 450mg, RT feeds $100 \mathrm{ml} @$ every $2^{\text {nd }}$ hourly, IVF 2 units DNS \& RL @ $75 \mathrm{ml} / \mathrm{hr}$, then they refer to Manipal hospital for further management. This patient came here with unconsciousness and they immediately shifted to ventilator. Medical neurologist treated with antibiotics, antifungals, mood stabilizers, IV fluids and with supportive measures. After five days, she came in to conscious.

\section{Investigations}

NMS is diagnosed based on clinical symptoms and past history includes usage of Antipsychotic drugs and lithium for several years. She has serum Lithium levels was found to be $2.01 \mathrm{mmol} / \mathrm{L}$ (Normal Range: 0.4-1.20). Magnetic Resonance Imaging shows Flair sulcal hyperintensities in both cerebral hemispheres suggestion of meningitis, Non-specific white matter hyperintense foci in bilateral frontal white matter. A Creatinine phospho kinase level was found to be890U/L (22-198U/L). Echocardiogram showsEjection fraction is $62 \%$, Fractional Shortening $31 \%$, Bradycardia, Normal cardiac chambers and Left Ventricular systolic function, Trivial Mitral Regurgitation/Tricuspid Regurgitation.

Ultrasonography shows Grade I fatty liver, mild sludge noted in gall bladder, Bilateral Grade I renal parenchymal changes for renal function test correlation. Chest X-Ray shows increased density in left hemi thorax - possibly due to effusion. Right lung fields are clear. Urine analysis shows neutral $\mathrm{p}^{\mathrm{H}}$ and normal urine analysis. An Electrolytes show Serum sodium levels are too high, initial day $150 \mathrm{mmol} / \mathrm{L}$ (135-145mmol/L) then gradually decreases and fifth day shows $161 \mathrm{mmol} / \mathrm{L}$, then progressively decreases. Serum potassium levels are in normal range. Serum chloride levels are also in normal range, but in day 6 the level is high $132 \mathrm{mmol} / \mathrm{L}$ (Normal Range: 95-105mmol/L). Liver Function Tests shows normal in ranges. Serum Creatinine levels are $1.6 \mathrm{mg} / \mathrm{dl}$ (Normal Range: $0.8-1.3 \mathrm{mg} / \mathrm{dl}$ ). In 
Complete Blood Count shows Haemoglobin from Day1- Day6 was 9.2, 9.0, 8.6, 7.4, 10.3, 9.1gm/dl (Normal Range: 12-14gm/dl) respectively. White Blood Cells show too high i.e., 148000, 16100 and 9500 cells $/ \mathrm{mm}^{3}$ (Normal Range: 4400-11000 cells $/ \mathrm{mm}^{3}$ ) from first three days and then gradually decreases the count. C-reactive protein levels are high76.2mg/dl (Normal Range: 1$3 \mathrm{mg} / \mathrm{dl})$.

\section{Treatment}

In Manipal Hospital, NMS is treated with Inj. Noradrenaline $48 \mathrm{cc} 15 \mathrm{ml} / \mathrm{hr} \& \mathrm{Inj}$. Vasopressin $48 \mathrm{ml}(3 \mathrm{ml} / \mathrm{hr})$ given to the patient from starting three days. Inj. Pantoprazole 40mg OD, Tab. Amantadine 100mg OD, Inj. Meaxon plus BD given from day1 to day11, Inj. Piperacillin + Tazobactam 4.5gm TID, Inj. Clarithromycin $500 \mathrm{mg}$ BD given from day1 to day2, Tab. Bromocriptine $2.5 \mathrm{mg}$ BD for first two days and TID for remaining days. Inj. Teicoplanin 40mg OD \& Inj. Meropenem 1gm TID were started after the culture report received, from day3 onwards started, Inj. Fluconazole 200mg OD started at day3 and Inj. Voriconazole 200mg BD started at day4 for high candidian growth observed in urine sample. Inj. Acetaminophen $1 \mathrm{gm}$ once a day given to the patient when the fever spikes occurred. Neb.Duolin \& Neb. Budecort started after extubated. Antipsychotic drugs like Tab. Risperidone and Tab. Ativan should be started after patient recovered at day 10 .

\section{Conclusion}

NMS is a complication related to usage of Antipsychotic drugs and Lithium toxicity. Treatment includes Bromocriptine, Amantadine, and other supportive medications to treat symptoms. The patient has clinical course up to 10days and then she recovered completely and normalized, she shifted to ward and then she discharged after three weeks with no complications related to the NMS.

\section{Reference}

1. Brian D. Berman Neuroleptic Malignant Syndrome: A Review for Neurohospitalists. Journals Permissions, 2011. DOI: $10.1177 / 1941875210386491$

2. M Unaldi, MB Sayhan, O Sogüt, R Demirhan, B Güzel, Neuroleptic malignant syndrome after the addition of lithium to risperidone treatment: a case report and review of the literature. HongKong journal of emergency medicine. Vol. 17(3) .Jul 2010

3. Ustündag M, Orak M, Güloglu C, Sayhan MB, Mahmut Tas M. A case of neuroleptic malignant syndrome induced by olanzapine in postpartum period. Indian $\mathbf{J}$ Psychiatry 2007; 49:287-9.

4. Duangjai Kasantikul *, Buranee Kanchanatawan, Neuroleptic Malignant Syndrome: A Review and Report of Six Cases. J Med Assoc Thai 2006; 89 (12): 2155-60.

5. Yanfen YANG, Yahui GUO, Aiguo ZHANG, Neuroleptic malignant syndrome in a patient treated with lithium carbonate and haloperidol. Shanghai Arch Psychiatry. 2014; 26(6): 368-370.

6. Geethan J. Chandran. Neuroleptic malignant syndrome: case report and discussion JAMC, SEPT. 2, 2003; 169 (5). 439-442.

7. Dua D, Grover S. Neuroleptic malignant syndrome in an elderly with quetiapine: A case report and review of literature. J Geriatr Ment Health 2017; 4:64-68.

8. Deepak Hanumanthaiah, Kumar Ramanathan. Olanzepine-induced neuroleptic malignant syndrome in a case of multiple sclerosis. Indian J Crit Care Med. 2014 Mar; 18(3): 178-180.

9. Martino Belvederi Murri, Argentina Guaglianone. Second-Generation Antipsychotics and Neuroleptic Malignant Syndrome: Systematic Review and Case 
Report Analysis. Drugs R D (2015) 15:45-

62.

10. Siddharth Sarkar, Nitin Gupta. Drug Information update. Atypical antipsychotics and neuroleptic malignant syndrome: nuances and pragmatics of the association. BJPsych Bullet in 2017. 41. 211-216.

\section{Abbreviations}

NMS: Neuroleptic Malignant Syndrome

GCS: Glasgow Coma Scale

E1V1M1: Eye, Verbal, Moments

IVF: Intravenous Fusion

DNS/RL: Dextrose Sodium Chloride/ Ringer

Lactate

ICU: Intensive Care Unit

Inj.: Injection

Neb: Nebulizer

Tab: Tablet

OD: Once in a day

BID: Twice in a day

TID: Thrice in a Day 